ISSN 2145-6054

\title{
PRETENSIONES Y ESTRATEGIA ${ }^{1}$ Claims and Strategy
}

\section{Wilson Yesid Suárez Manrique ${ }^{2}$}

Fecha de recepción: 18 de marzo de 2015

Fecha de aceptación: 12 de mayo de 2015

SUMARIO: 1. Introducción; 2. Objeto y método en torno al concepto de Estado; 3. Antecedentes y concepto de la teoría del Estado; 4. Estructura del Estado; 5. Potestades y funciones del Estado; 6. Conclusiones; 7. Referencias bibliográficas.

\footnotetext{
${ }^{1}$ Artículo de investigación producto del proyecto de investigación "El juez en el Estado Constitucional", desarrollado al interior de la octava convocatoria interna de la Universidad Santo Tomás Bucaramanga.

${ }^{2}$ Doctor en Estado de Derecho y Gobernanza Global de la Universidad de Salamanca. Magister en Derecho de la Universidad Industrial de Santander. Profesor e investigador de la Universidad Santo Tomás Bucaramanga. Coordinador de la especialización en Derecho Constitucional y del Observatorio en Derecho Constitucional de la Universidad Santo Tomás. Correo electrónico: wilsonyesidsuarez@ gmail.com. Código postal 681004.
} 


\section{COMO SE CITA ESTE ARTÍCULO (APA 6)}

Suárez Manrique, Wilson Yesid (2016). Pretensiones y Estrategia. Revista Jurídica Mario Alario D’Filippo, VIII (15), pág 12-28.

\section{RESUMEN}

El artículo describe y analiza la relación que existe entre la forma de presentar las pretensiones de la tutela y la influencia que esta genera en la decisión del juez. Se prescribe un modelo de redacción de las pretensiones de la tutela, basado en la concepción estructural de los derechos fundamentales, la conciencia del principio de consonancia, la racionalidad limitada del juez, y el principio meta-jurídico de claridad y simplicidad. El artículo se estructura en cuatro partes. En la primera se presenta un análisis de los requisitos de procedencia de la acción de tutela; con la finalidad de mostrar el avance en la formalización de éstos. En la segunda se analiza el principio de congruencia en la tutela; en aras a presentar los límites y libertades del juez constitucional al momento de fallar. En la tercera, se toma los resultados de las partes anteriores, y se narran las principales objeciones al modelo informal de redacción de las pretensiones. En la cuarta se presenta una alternativa constitucional, lógica, móvil y práctica sobre cómo establecer las pretensiones de la tutela.

\section{PALABRAS CLAVES}

Derechos fundamentales, juez, pretensiones, argumentos.

\section{ABSTRACT}

The article describes and analyzes the relationship between how to present the claims of the tutelage and influence it generates in the judge's decision. Standard wording of the claims of guardianship, based on the structural design of fundamental rights is prescribed, awareness of the principle of consonance, limited rationality of the judge, and the meta-legal principle of clarity and simplicity. The article is divided into four parts. In the first analysis of the procedural requirements of the tutela it is presented; in order to show progress in formalizing them. In the second the principle of consistency in the protection analyzes; in order to present the limits of constitutional freedoms and judge at the time of failure. In the third, the results of the above parts is taken, and the main objections are narrated the informal model of drafting the claims. In the fourth a logical practice on how to establish the claims of constitutional protection alternative, mobile and presents.

\section{KEYWORDS}

Fundamental rights, judge, claims, arguments. 


\section{INTRODUCCIÓN}

La Corte Constitucional de Colombia en la sentencia T-152 de 2013, revisó el caso de Johanna Yepes y Enrique Romero. El 1 de abril del 2000, en el Municipio de Icononzo, un grupo de Autodefensas Unidas de Colombia, con la presunta complacencia de autoridades militares y de policía, los asesinó. Los familiares de las victimas presentaron demanda de reparación directa, la cual fue negada en segunda instancia y en el Consejo de Estado. La Corte Constitucional ordenó revocar tales sentencias porque a su juicio se había trasgredido el principio de consonancia (Rojas, 2006) con las pretensiones de la acción de reparación directa.

Los nuevos paradigmas constitucionales (Bernal, 2007), y la forma como estos han sido adoptados por los altos órganos judiciales (Sáchica, 2000), han tensionado la forma clásica en la que se entendía, estudiaba y ejercía el derecho (López, 2004), generando múltiples aporías y un campo fecundo para la reflexión y el mejoramiento de las prácticas de los juristas. Pueden considerarse, por cuestiones expositivas y tradicionalistas, dos modelos generales en relación con el establecimiento de las pretensiones en los procesos o acciones judiciales: un modelo especialmente riguroso y otro especialmente flexible. El primer modelo se encuentra ejemplificado en los casos en los cuales se exige una técnica o unos condicionamientos en la forma de establecer las pretensiones, a consecuencia de que el establecimiento inadecuado retarde o implique la inadmisión o el rechazo de la acción o el recurso. Las formas tradicionales como se entendió el recurso extraordinario de casación (Camacho, 1983) y su tecnicismo en el ítem petitorio especifican esta idea. En este caso se establece una especial carga en quien presenta la acción y una actitud pasiva en cabeza del juez. La información importante debe ser suministrada de abajo hacia arriba.

El segundo modelo se ejemplifica en los casos en los cuales no se exigen condicionamientos rigurosos a efectos de establecer las pretensiones de la acción, como en el caso de la acción de tutela o de amparo (Quinche, 2015), por lo cual, la falta de técnica de quien promueve la acción no implica, en principio, consecuencias negativas en su contra. Pues, el juez debe ostentar un rol activo en aras a la protección de los derechos fundamentales (Suárez, 2014). La información si no es suministrada adecuadamente debe ser gestionada de arriba hacia abajo.

A diferencia de como existe, por ejemplo, en la jurisdicción civil (López, 1983) o administrativa, o en el caso de los recursos extraordinarios, una técnica depurada para redactar las acciones en general y las pretensiones en especial, en donde la mala elección de éstas podría llevar al traste la acción. En el trámite de tutela por los principios de informalidad y sumariedad (Quinche, 2007), no preexisten requerimientos rigurosos para la presentación de la acción, salvo los establecidos en el artículo 14 del Decreto 2591 de 1991 y los exigidos jurisprudencialmente. Esta deficiencia en la información relevante 
sobre lo solicitado debe ser surtida por una labor activa del juez, una interpretación amplia de la constitución, y por un mayor peso de la buena fe.

En principio, el hecho de establecer de manera poco clara o inadecuada, las pretensiones de la acción de tutela no condicionan el éxito de la acción. En estos casos es el juez en virtud del su papel activo en el trámite constitucional (Suarez, 2014), es el encargado de impartir las órdenes correspondientes ante la afectación de los derechos fundamentales (Alexy, 2002), y entablar un dialogo entre la constitución y la vida de las personas.

Una interpretación amplia y literalista (López, 2006) del artículo 86 de la CP, conlleva a que las pretensiones de la tutela, en un alto grado de abstracción, se condensan en la orden de protección inmediata a los derechos fundamentales. Situación que puede, como más adelante se muestra, generar múltiples aporías. Pues, debe ser traducida al caso en concreto.

Sin embargo, que el establecer de forma adecuada las pretensiones de la tutela no sea una carga como tal, no significa que no pueda hacerse de forma plausible. Existen diversas formas de pensar o establecer las pretensiones de la acción de tutela, luego, se hace importante escoger entre las diferentes alternativas la que se considere más adecuada para lograr la protección de los derechos fundamentales. Una mala redacción de las pretensiones de la acción puede conllevar consecuencias desfavorables en la sentencia.

En este artículo se defiende la tesis de que la redacción de las pretensiones de la tutela, la manera cómo estas sean establecidas, pese a que no exista una exigencia constitucional o legal directa, influencia de una manera importante la decisión del juez, y, en correlato, repercute en la protección de los derechos fundamentales. Un diseño adecuado de las pretensiones de la acción de tutela, desde una perspectiva dinámica, simple, coherente y lógica, puede repercutir de forma importante en la garantía de los derechos fundamentales.

Para cumplir con esta finalidad el texto se divide en cuatro partes. En la primera se presenta una reflexión general acerca de los requisitos de procedencia de la acción de tutela. En la segunda se muestra el principio de congruencia de la sentencia desde la perspectiva del trámite constitucional y las facultades del juez de tutela al momento de proferir sentencia. En la tercera se exhiben las principales objeciones al modelo informal de redacción de las pretensiones. En la cuarta se presenta una alternativa constitucional, lógica, móvil y práctica sobre cómo establecer las pretensiones de la tutela. Así pues, el primer argumento refiere a que determinar las pretensiones de la tutela no es un requisito de presentación de la acción, empero tampoco existe impedimento para determinarlas; el segundo, alude a que en el trámite constitucional no se aplica el principio de congruencia, por lo que el juez está dotado con un amplio margen de discrecionalidad para la protección de los derechos fundamentales, sin embargo esto puede tensionar 
derechos fundamentales del accionado a su vez que comporta limitantes cognitivas del juez; el cuarto argumento refiere, con base en lo anterior, a que pueden presentarse de una manera plausible las pretensiones de la tutela, lo que conlleva a una mejor posibilidad de éxito en la acción y de protección dinámica de los derechos fundamentales, desde una perspectiva estructural.

\section{PRESUPUESTOS DE TUTELA E INFORMALIDAD}

Que no exista un requerimiento específico para establecer las pretensiones no implica que establecerlas esté prohibido. Luego existe un amplio margen de acción para el jurista (Carrio, 1995). Sin embargo, la redacción inadecuada de las pretensiones de la tutela puede conllevar a que los derechos fundamentales no se protejan de manera adecuada.

La informalidad que caracterizó la acción de tutela en sus etapas iniciales ha venido desgastándose (Quinche, 2007). La jurisprudencia ha venido, ante lo sensible del asunto, estableciendo requisitos cada vez más exigentes para la presentación o procedencia de la acción de tutela. Actualmente puede hablarse de cuatro clases de requisitos generales de la tutela.

Estas cuatro categorías son: presupuestos constitucionales generales de la acción; presupuestos generales de la presentación, presupuestos generales de procedibilidad, y presupuestos específicos de procedibilidad. Los primeros son los presupuestos constitucionales exigidos por el artículo 86 de la Constitución, que refieren a los elementos esenciales para el trámite constitucional. Los segundos, son los establecidos en el artículo 14 del Decreto 2591 de 1991, y están referidos a los requerimientos formales para la presentación de la acción. Los terceros han sido establecidos por vía de interpretación por la Corte Constitucional, y refieren a los elementos necesarios para obtener un pronunciamiento de fondo y favorable, pero que no se valoran tanto en el inicio del trámite sino, especialmente, en la sentencia, y por los cuales, de no ser satisfechos se generará una sentencia que declara la improcedencia de la acción. Los cuartos, son requisitos establecidos por vía jurisprudencial cuando se trate de trámites de tutela específicos (Quinche, 2013), como el caso de la tutela contra providencias judiciales, sentencia de la Corte Constitucional C 590 de 2005, o de tutela por estabilidad laboral reforzada, sentencia de la Corte Constitucional, T 098 de 2015.

En cuanto a los requisitos constitucionales generales, el artículo 86 de la Constitución Política, preceptúa:

Toda persona tendrá acción de tutela para reclamar ante los jueces (...) la protección inmediata de sus derechos constitucionales fundamentales, cuando quiera que éstos resulten vulnerados o amenazados por la acción o la omisión de cualquier autoridad pública. La protección consistirá en una orden para que aquel respecto de quien se solicita la tutela, actúe o se abstenga de hacerlo. (A. Constituyente, 1991). 
De esta cita constitucional se extraen tres ideas generales relacionadas con la tesis del escrito: la finalidad de la acción, el presupuesto abstracto, y el sentido de la decisión (Alexei, 2002). La finalidad de la tutela, a grandes trazos, consiste en la protección inmediata de los derechos fundamentales; el presupuesto abstracto refiere a la vulneración o amenaza de los derechos fundamentales; y el sentido de la decisión a una orden para que el accionado haga u omita algo. De estos tres presupuestos se infiere que, en un alto grado de conceptualización, el objeto genérico de la acción, su pretensión esencial, es la protección de los derechos fundamentales en el sentido de ordenar una acción u omisión.

Por su parte, el artículo 14 del Decreto 2591 de 1991, establece cinco requisitos generales para la presentación de la acción. Requiere que se describan en la tutela las situaciones de hecho que motivan la acción (1), el presunto derecho vulnerado (2), la identificación del accionado -si fuere posible- (3), la descripción de los demás hechos relevantes (4), y la identificación del accionante junto con su residencia (5). Además de ello, como forma de resaltar la informalidad del trámite el Decreto establece que la tutela puede presentarse verbalmente y que no es requisito del trámite el agotamiento de la vía gubernativa ${ }^{3}$. En este desarrollo reglamentario, no se establece específicamente la necesidad de establecer las pretensiones en la acción de tutela ni mucho menos una tecnicidad en las mismas, pues se parte del papel proactivo del juez constitucional (Suárez, 2014). De forma general este precepto lo que hace es especificar el mandato constitucional en el entendido de direccionar los tres presupuestos generales.

Estos requisitos deben ser leídos de conformidad con las causales de improcedencia de la acción de tutela, establecidas, especialmente en el artículo 6 del Decreto 2591 de 1991 (Quinche, 2015), y con las reglas jurisprudenciales generales establecidas por la Corte Constitucional. Como por ejemplo, en la capital sentencia C 590 de 2005, en donde se establecen requisitos generales de procedencia de la acción de tutela, tales como: la relevancia constitucional, el agotamiento de los medios ordinarios y extraordinarios de defensa judicial, el principio de inmediatez, la irregularidad procesal determinate, que la parte actora identifique de manera razonable tanto los hechos que generaron la vulneración como los derechos vulnerados y que hubiere alegado tal vulneración en el proceso judicial siempre que esto hubiere sido posible, y que no se trate de tutela contra tutela (Quinche, 2015).

Además de las posibles exigencias ulteriores establecidas para la protección de los derechos fundamentales, resulta importante revisar el hecho que dentro de estas interpelaciones para la presentación y procedencia de la acción de tutela no se encuentra la de la identificación clara y coherente de las pretensiones de la acción. Tampoco se

\footnotetext{
${ }^{3}$ El artículo 14 establece: En la solicitud de tutela se expresará, con la mayor claridad posible, la acción o la omisión que la motiva, el derecho que se considera violado o amenazado, el nombre de la autoridad pública, si fuere posible, o del órgano autor de la amenaza o del agravio, y la descripción de las demás circunstancias relevantes para decidir la solicitud. También contendrá el nombre y el lugar de residencia del solicitante."
} 
encuentra en los supuestos anteriores que la falta de identificación de las pretensiones conlleve una consecuencia adversa contra el accionante. No obstante, que no se haya establecido como tal, no quiere decir que no puedan implantarse; tampoco significa que puedan ser establecidas de cualquier forma si lo que se desea es tener éxito en la acción.

Lo sumario del trámite y su característica de preferente (Quinche, 2015) tiene por finalidad lograr una pronta respuesta para la protección de las posiciones más básicas e importantes en el ordenamiento jurídico. Si se hubiese establecido un procedimiento técnico y complejo para la protección de los derechos fundamentales podría, en principio, reducirse la forma de protección. A mayor cantidad de exigencias podría pensarse que la protección se reduciría porque sería "más costoso" (Calderón, 2011) acceder al procedimiento. Por ello es que, en principio, los requerimientos tienden a condesarse en la información más necesaria para la solución del caso sin entrar en tecnicismos exagerados (Alexei, 2002). Pues, la situación contraria y extrema, piénsese por ejemplo en los más intensos tecnicismos para la presentación de la acción, implicarían mayores costos para la presentación de la acción, lo que desincentivaría su uso y protección. Ello podría verse como una protección deficiente de los derechos fundamentales.

Sin embargo, no es descartable pensar que la informalidad del trámite de la acción de tutela puede conllevar a una menor protección de los derechos fundamentales. Lo que se quiso evitarse se vuelve en contra. La informalidad de los trámites puede implicar que aumente el número de improcedencias de la acción de tutela o que esta tenga pocas posibilidades de éxito. Pues, no se le presta la suficiente atención al escrito, no es claro el objeto de la tutela, al juez se le dificulta entender el caso y lo pedido. Gran parte de las acciones de tutela que no cumplen con su finalidad tiene como lastre una inadecuada redacción de las pretensiones y poca reflexión en relación a la forma como estas se relacionan con las demás partes del escrito.

En correlato, una exigencia mínima o adecuada en la presentación de la tutela, para el caso de las pretensiones, puede facilitar la labor del juez y conllevar una mejor protección de los derechos fundamentales. El establecimiento de unos supuestos mínimos para la presentación de acción, que no se constituyen en exigencias legales, si no en buenas prácticas jurídicas, puede elevar la posibilidad del éxito de recibir una sentencia favorable. De lo que se trata es de plantear una exigencia moderada, que no permita siempre la extrema informalidad ni que se condense en un tecnicismo exagerado. Así las cosas, la inversión de costos ex ante a la presentación de la acción de tutela, puede contribuir a ahorrar costos ex post (Cooter, 2000) relativos, especialmente, a una sentencia de tutela desfavorable.

\section{EL PRINCIPIO DE CONSONANCIA Y LOS LÍMITES JUDICIALES}

En la jurisdicción ordinaria y el litigio tradicional el principio de consonancia se establecía como un límite importante de las facultades del juez al momento de proferir sentencia, 
quien se encontraba atado a las pretensiones y excepciones de la demanda ${ }^{4}$. En el trámite constitucional dicho principio ostenta una visión diferente que presenta una reconfiguración de la forma de decidir los litigios y que referencia las pretensiones de la acción de tutela como un punto de partida pero no de llegada.

La Corte Constitucional ha establecido sobre el principio de consonancia lo siguiente:

"En términos sencillos, puede afirmarse que el principio de consonancia establece que la competencia funcional del juez se restringe al pedido de las partes; es decir, a las súplicas de la demanda y a las excepciones propuestas por la contraparte".

Devis Hernando lo define como "el principio normativo que delimita el contenido de las resoluciones judiciales que deben proferirse, de acuerdo con el sentido y alcance de las peticiones formuladas por las partes (en lo civil, laboral, y contencioso-administrativo)... para el efecto de que exista identidad jurídica entre lo resuelto y las pretensiones o imputaciones" (Devis, 1985).

De estas dos citas se destacan cuatro ideas generales. La primera: quien instaura la demanda, es quien delimita en principio el objeto del litigio. Segundo: el juez no puede librarse, salvo casos excepcionales, de los límites impuestos. Tercero: las resoluciones por fuera de lo pedido, en la mayoría de los casos, afrentan el principio de consonancia. Cuarto, que la consonancia es garantía de legalidad y del derecho de defensa.

Por la jerarquía de los derechos fundamentales, y su necesaria protección dentro del ordenamiento jurídico, al representar el objeto jurídico de máxima importancia (Carbonell, 2007), las limitaciones impuestas por el principio de consonancia, se ven disueltas dentro de la sentencia de tutela. Debido a que el juez encuentra un nuevo rol dentro de su labor constitucional, el cual de cierta forma resta cargas a quien impetra la acción. Se trata de un juez súper poderoso (Quinche, 2015). Un juez que no se encuentra atado a las cadenas o a los límites impuestos por las pretensiones de la tutela sino que puede fallar más halla o fallar diferente a lo solicitado. Luego este principio de consonancia vendría a ser, si no sobrepasado, limitado a una expresión compatible con la protección de los derechos fundamentales.

Así pues, la naturaleza constitucional de la acción de tutela, lleva implícita prerrogativas de importancia trascendental, al proteger las posiciones más importantes. Lo cual, le otorga un papel especial al juez (Suárez, 2014), quien no se encuentra tanto en el campo de derechos patrimoniales y disponibles, si no en la garantía de los derechos fundamentales (Suárez, 2014). Por lo que, ha sido dotado de mayores facultades de decisión. El objeto

\footnotetext{
${ }^{4}$ El artículo 281 de Código General del Proceso, establece "La sentencia deberá estar en consonancia con los hechos y las pretensiones aducidos en la demanda y en las demás oportunidades que este código contempla y con las excepciones que aparezcan probadas y hubieren sido alegadas si así lo exige la ley. No podrá condenarse al demandado por cantidad superior o por objeto distinto del pretendido en la demanda ni por causa diferente a la invocada en esta".
} 
de la acción, su naturaleza, conllevan a variar el rol del juez y sus poderes de decisión (Quinche, 2015).

El principio de consonancia se modifica en dos sentidos: en cuanto a fallar diferente de lo pedido y con fundamento diferente. La Corte Constitucional en la sentencia T 310 de 1995, estableció:

Para la Sala es claro que, dada la naturaleza de la presente acción, la labor del juez no debe circunscribirse únicamente a las pretensiones que cualquier persona exponga en la respectiva demanda, sino que su labor debe estar encaminada a garantizar la vigencia y la efectividad de los preceptos constitucionales relativos al amparo inmediato y necesario de los derechos fundamentales. En otras palabras, en materia de tutela no sólo resulta procedente sino que en algunas ocasiones se torna indispensable que los fallos sean extra o ultra petita (C. Constitucional, 1995).

De esta forma, la facultad de fallar ultra y extra petita no solo refiere a la forma de protección de los derechos vulnerados o amenazados, sino que también refiere al fundamento de la decisión, es decir a los derechos que se alegaron como vulnerados. No solo se trata de que el juez estime que determinada ordenen conlleva a proteger de mejor forma los derechos vulnerados si no que vas hasta el punto de poder determinar que el derecho vulnerado es otro o que los derechos vulnerados son diferentes, por lo cual la orden ha de ser impartida con distintos alcances.

La Corte Constitucional en la sentencia T 886 de 2000, preceptuó:

(...) reviste al juez que conoce de ella de una serie de facultades que, en ejercicio de la jurisdicción ordinaria, no posee. La principal de ellas, consiste en fallar más allá de lo solicitado por quien hace uso de este mecanismo, fallos ultra o extra petita. Prerrogativa que permite al juez de tutela pronunciarse sobre aspectos que, sin ser expuestos como fundamento del amparo solicitado, deben ser objeto de pronunciamiento, por estar vulnerando o impidiendo la efectividad de derechos de rango constitucional fundamental. (C. Constitucional, 2000).

No existe, pues, la necesidad de establecer las pretensiones de la tutela como una limitante a la potestad del juez; es decir, que éste no se encuentra atado por ellas y los límites que impondría el principio de congruencia. La Corte Constitucional en la sentencia T 464 de 2012, dispuso "[e]ntonces, existe la posibilidad de que el juez de tutela pueda ordenar la protección judicial de uno o más derechos fundamentales que se encuentren presuntamente conculcados, así el accionante no lo hubiese pedido expresamente en la acción de tutela" (C. Constitucional, 2012).

Sin embargo, estas facultades del juez al momento de decidir la tutela tensionan de manera profunda determinados principios y derechos fundamentales. No puede del todo afirmarse que el principio de consonancia no ostente ninguna aplicación en el 
trámite de tutela, si no que cabría pensar mejor en que el principio ha sido debilitado, pues la expresión de su eliminación parecería conllevar implícitamente la trasgresión de los derechos fundamentales de la parte accionada. Pues, no se le garantizaría el derecho de defensa e igualdad, al verse, en muchos casos, sometido a sentencias respecto de las cuales no pudieron defenderse de manera efectiva. Lo cual implicaría una sentencia sustancialmente contradictoria. Luego, el juez de tutela debe ser activo en el evento de que la protección y el debilitamiento de la consonancia no conlleven la afectación de los derechos fundamentales de los involucrados.

\section{LAS OBJECIONES AL MODELO INFORMAL}

La informalidad en el trámite de tutela que repercute en la informalidad para la presentación de las pretensiones en la acción, lo cual descarga al accionante y exige proactividad al juez (Suárez, 2014), está fundada en la necesaria protección de los derechos fundamentales y la corresponsabilidad en la protección de éstos por parte de las diferentes entidades estatales (Bernal, 2006). Esta fundada especialmente en la protección superlativa de los derechos fundamentales y las formas como estos pueden ser garantizados de una forma óptima (Alexy, 2002). Esta forma de concebir las exigencias en la redacción de las pretensiones de tutela ostenta como elementos positivos: el proteccionismo, la celeridad (Quinche, 2015), el acceso a la administración de justicia (Suárez, 2014), la tutela judicial efectiva y la proactividad del juez.

Esta perspectiva de la acción, además de la especial protección que requieren los derechos fundamentales, permite celeridad en el trámite de la acción pues si los requisitos fuesen rigurosos se podría dar pie al rechazo o la inadmisión de la acción o cuan siquiera al retardo de la misma, por lo que no garantizaría su efectividad y adecuada protección.

La inadmisión o los requerimientos inoficiosos en la presentación, para el caso en la redacción de las pretensiones de la tutela, podría a su vez ser considerado como una forma de limitar el acceso a la administración de justicia y a la tutela judicial efectiva, como lo sostuvo la Corte en la sentencia T 103 de 2014. En la medida en que dificulta la protección de los derechos fundamentales de las personas al establecer lineamientos y supuestos innecesarios para su protección.

Además de lo anterior, la informalidad conlleva a involucrar al juez con la protección de los derechos fundamentales, especialmente desde la perspectiva de exigir su conocimiento y proactividad en la protección de los mismos, al concederle poderes y facultades especiales (López, 2006) acordes con la naturaleza del asunto que desea resolver y teniendo como finalidad especial la protección de los derechos fundamentales.

Los anteriores argumentos pueden ser englobados bajo lo que en este escrito se llama "el mito de la informalidad", pues bajo él se solapan cuestionamientos que no 
son fácilmente debatibles con las premisas antedichas. Las principales objeciones que pueden proponérsele al mito son: el conocimiento incompleto del juez, las limitantes temporales, la cantidad de asuntos a resolver, la forma de satisfacción de los derechos y la afectación al derecho de defensa. De forma general puede decirse que se dejan cosas muy importantes por definir en las manos del juez.

La informalidad en el trámite, y en las pretensiones, repercute de cierta forma en el conocimiento que el juez ostenta de la situación; el argumento general es que el juez ostenta un conocimiento muy escueto de los aspectos jurídicamente relevantes, es decir, no conoce bien, para el caso, cuales son los requerimientos de la acción, especialmente bajo el entendido de que un derecho fundamental ostenta múltiples facetas prestacionales y que estas pueden ser cumplidas en distinta forma (Alexy, 2002).

Este conocimiento incompleto del juez, como caso particular de racionalidad limitada (Curzio, 1998) se ve agravado por el hecho que los términos para decidir la acción son muy cortos, para el caso colombiano se tratan de 10 días. Este corto lapso implica que las falencias cognitivas sobre los aspectos jurídicamente relevantes de las pretensiones (a los cuales se encuentran ligados los que soportan la acción), no pueden ser suplidas fácilmente con las etapas procesales o con la declaración de pruebas dentro del trámite; el juez se encuentra en una especie de racionalidad acotada (Herbert, 1985).

La situación parece complicarse en la medida que los jueces encargados de resolver los asuntos están ataviados con una carga de trabajo considerable, pues, no solo son jueces constitucionales sino que además son jueces de distintas jurisdicciones y deben resolver múltiples tutelas de manera simultánea.

Sumado a ello está el evento que en los casos de ciertos derechos quien conoce la mejor forma de repararlos o protegerlos es el propio titular de los derechos fundamentales. En casos relativos a la salud en los cuales se trata de otorgar un medicamento o conceder un procedimiento podría entenderse de forma simple el sentido de la orden, sin embargo en casos como trasgresiones a la intimidad, el buen nombre, la dignidad, por la naturaleza de esos derechos, la forma de repararlos la conoce en mejor forma el titular afectado (Rivera, 2007). Es el titular quien puede solicitar la mejor forma de protección de los mismos, teniendo en cuenta las distintas facetas (Alexy, 2002) y el grado de desarrollo de tales derechos.

La consonancia, por su parte, es una forma de garantizar el derecho de defensa (Devis, 1985). Si el accionado en el trámite de tutela no conoce la solicitud de tutela o los fundamentos de ella, difícilmente puede garantizársele una defensa adecuada, así lo dispuso Corte Constitucional en la sentencia C 025 de 2010. No le resulta fácil defenderse de la acción sin entender meridianamente cuales son las pretensiones del accionante. 
Así las cosas, no se encuentra el juez en condiciones óptimas para fallar. En muchas ocasiones puede decirse que falla con apuestas o que prefiere decretar la improcedencia de la tutela. La impresión general, que se desea presentar y sintetizar a esta altura del discurso, es que la informalidad del establecimiento de las pretensiones de la acción de tutela no conlleva del todo situaciones positivas para quien presenta la acción, sino que, especialmente, puede llevar a situaciones en contra de la protección de sus derechos.

\section{EL MODELO SUGERIDO}

No obstante, que no exista requerimiento legal en dicho sentido, es posible establecer las pretensiones de la acción de tutela, y para ello hay un importante campo de acción; alternativas dentro de las cuales se debe escoger la que permita llegar con mayor probabilidad de éxito a la protección de los derechos fundamentales (tanto del accionante como del accionado). Dentro de estas posibles alternativas, un adecuado establecimiento de las mismas, si bien no garantiza el éxito de la acción, puede influir positivamente o al menos evitar ciertas situaciones jurídicamente indeseables.

Además de partir del hecho que las pretensiones de la tutela pueden ser establecidas de diferente forma, se hace necesario partir de que las elecciones que se tomen en este sentido influencian de diferente forma el sentido del fallo. No es la única forma de influenciar el sentido del fallo, pues, los hechos, las pruebas, y la fundamentación jurídica también cumplen esa labor, sin embargo, es parte considerable dentro del proceso.

Si es posible realizar determinadas elecciones para el establecimiento, y ello influye en la decisión, podría pensarse que puede existir formas mejores de realizar esa labor, o por lo menos situaciones que pueden mejorarse o errores que pueden evitarse. La elección de las diferentes alternativas y sus consecuencias dependen de los puntos referenciales que se tomen para ello. A continuación se presenta y sugiere un modelo que media entre la concepción especialmente rigurosa y la especialmente flexible; modelo que se integra por ciertas estratagemas (Carofiglio, 2010) que pueden ser elementos argumentativos generales para coadyuvar el éxito de la presentación de la acción de tutela, teniendo en cuenta, especialmente, las limitantes epistemológicas, laborales y temporales que ostenta el juez (Posner, 2011).

Así pues, según los requisitos referidos (la afectación o amenaza de los derechos fundamentales), y los poderes del juez, se propone una cierta tecnicidad meridiana, que consulta la naturaleza de la acción, y una visión racional de las alternativas escogidas. La propuesta sugerida se categoriza bajo, el principio de la "simplicidad y claridad", el cual trata de cubrir las limitantes judiciales desde una perspectiva sencilla y lógica. Entiende las deficiencias cognitivas y temporales del juez y del proceso, desea facilitar el trabajo, apropiarse del poder simbólico de la información, y exponer lo necesario desde una concepción estructural de los derechos fundamentales. 
Alexy propone entender los derechos fundamentales como una relación tríadica de un titular, respecto a un destinatario en cuanto a determinado objeto, y lo representa de esta forma: RabG (Alexy, 2002). Dependiendo si se establece el destinatario cómo el estado o un particular se está en el campo de derechos fundamentales públicos o privados, en el entendido de identificar si la acción se dirige hacia la entidad pública o el sujeto privado (Alexei, 2000). El objeto corresponde a una acción, bien sea positiva o negativa. De no ser así, no tendría sentido incluir al destinatario dentro de la relación.

Dentro de la acción de tutela se hace importante para la redacción de las pretensiones de la acción el tener meridiana claridad sobre estas posiciones básicas y su movilidad. Debe identificarse el derecho, sus destinatarios y el objeto del mismo (junto con sus facetas y alcances) para el establecimiento de las pretensiones de la acción.

Teniendo en cuenta lo anterior, y que tiene la tutela por finalidad lograr una protección adecuada de los derechos fundamentales, se proponen cinco etapas generales para la redacción de las pretensiones de la tutela. En primer lugar se debe iniciar con la declaración de la afectación o vulneración de los derechos fundamentales. Como lo establece el artículo 86 de la CP, la tutela ostenta vocación de prosperidad cuando parte de la afectación o amenaza de los derechos fundamentales. Luego, la primera pretensión de la acción de tutela ha de estar encaminada a que el juez declare que el accionado está afectando los derechos fundamentales del accionante. Así las cosas, la pretensión primera, estaría redactada en un sentido similar al siguiente: Se declare que el accionado " $b$ ", mediante la conducta "G", vulneró el derecho fundamental DF del cual es titular "a". En este sentido es importante notar que la conducta del destinatario puede ser plural, estar constituida por acciones y omisiones, y que puede afectar no solamente uno sino varios derechos fundamentales. En caso de que se afecten varios derechos fundamentales es aconsejable estipular el mayor número de ellos, en la medida que se tendrían mayor fuerza en la negociación.

En segundo lugar, se debe solicitar, de manera general, la protección de los derechos fundamentales que están siendo afectados por la persona accionada en la tutela. Luego la segunda pretensión de la tutela está encaminada a que el juez proteja de manera inmediata e integral los derechos fundamentales. La orden inmediata desea fijar límites temporales y la integral que se protejan los aspectos relevantes de los derechos fundamentales que están siendo afectados. El énfasis importante en esta pretensión debe recaer sobre el titular del derecho fundamental, desde la perspectiva que debe ser presentado como una persona en un estado grave de debilidad, de afectación, por las conductas del destinatario del derecho fundamental. Esta solicitud es general en la medida en que se predisponga un sentido en la decisión a tomar, y se pueda conducir al juez, de manera inconsciente, en determinada dirección. 
En tercer lugar, se debe requerir que se imparten las órdenes para que cese la afectación de los derechos fundamentales. Es decir que se debe solicitar de manera específica las medidas que se consideren necesarias para que se protejan los derechos fundamentales. El énfasis de esta pretensión recae especialmente sobre el objeto ${ }^{5}$. De esta forma se especifica la pretensión segunda, de conformidad con la afectación realizada en la pretensión primera. Teniendo en cuenta la forma de protección más adecuada que se da para el caso de los derechos fundamentales de conformidad con su naturaleza. Se hace importante la reconstrucción estructural de los derechos fundamentales en la medida que al limitar la afectación de los derechos fundamentales, sus dimensiones, y la intensidad del daño, se permite especificar las medidas de protección de los mismos.

Con lo anterior, se podría pensar que se cumple con la finalidad de la acción de tutela, sin embargo, resulta plausible establecer otro tipo de pretensiones a efectos de realizar en mejor medida la protección de los derechos fundamentales. Luego se debe, en cuarto lugar, solicitar que se preste en lo sucesivo una protección integral, ejemplo de esto lo establecido por la Corte Constitucional en la sentencia T 750 de 2014. Con lo cual se utiliza una especie de clausula cajón de sastre (Cohen, 2009) de la que se pueden derivar pretensiones o acciones más específicas que se encuentran relacionadas con las primeras pretensiones, empero que por diversos motivos no pudieron especificarse en el trámite de la acción.

En quinto lugar, se sugiere solicitar que se ordene al accionado abstenerse en un futuro de seguir realizando la misma conducta u omisión que generó la acción. El hecho de realizar esta pretensión conlleva a que si en un futuro nuevamente se realiza la afectación a los derechos fundamentales este caso pueda ser ventilado como incidente en el proceso que ya fue fallado y no se haga necesario establecer otro nuevo para la protección de los eventos que se protegieron en la primera caso. De esta forma se ahorran costos del proceso y se está en una posición futura estratégica respecto de la protección del derecho.

\section{CONCLUSIONES}

Entre un modelo tendencialmente riguroso y otro tendencialmente flexible, el establecimiento de las pretensiones de la tutela se encuentra inserto en éste último. Pese a la existencia, gestación y consolidación de requisitos generales de la tutela, requisitos de presentación de la acción, presupuestos generales de procedibilidad, y presupuestos específicos de procedibilidad, el establecimiento de las pretensiones de la acción siguen rigiéndose por el principio de informalidad.

\footnotetext{
${ }^{5}$ Ahora bien, entender estructuralmente la concepción de los derechos fundamentales es muy importante para el diseño general de la acción de tutela y para la redacción de las pretensiones de la misma. Luego de que se han revisado las distintas etapas, resulta importante, identificar los elementos en los que se debe concretar. El hecho de establecer esquemáticamente el titular del derecho, el destinatario y el objeto del mismo, permite determinar las afectaciones y la forma en que estas pueden ser satisfechas.
} 
El "mito de la informalidad" que pretende garantizar la protección de los derechos fundamentales, la celeridad y la tutela judicial efectiva, termina por ser una forma de afectación de los derechos fundamentales y una protección deficiente de los mismos. Situación que se agrava si se tiene en cuenta la desprotección de los derechos de defensa del accionado derivada de la relectura del principio de consonancia y de las exigencias estridentes realizadas a los jueces de tutela. Pues, estos deben fallar con conocimiento incompleto, limitantes temporales, congestión judicial evidente, y afectando el derecho de defensa del accionado.

Por ello, se sugiere la utilización de un modelo moderado que tenga la potencialidad de proteger de mejor manera los derechos fundamentales de los involucrados; el cual se inspire en la retórica, se integre por estratagema como elementos argumentativos y tenga en cuenta, especialmente, las limitantes epistemológicas, laborales y temporales que ostenta el juez. Se trata de un modelo integrado por cinco gradas. En la primera el énfasis recae en el accionado, al exhibir la afectación, desde una perspectiva estructural a los derechos fundamentales. En la segunda el acento se implica en el accionantetitular, al solicitar la protección de sus derechos fundamentales. En la tercera se enfoca especialmente el objeto de protección. En la cuarta se puntualiza a manera de clausula abierta la protección integral. Y en la quinta se simplifican las afectaciones que se liguen entre el presente y el futuro del asunto.

\section{REFERENCIAS BILBIOGRÁFICAS}

ALEXEI, J. (2002) "La eficacia de los derechos fundamentales entre particulares". Bogotá: Universidad Externado de Colombia.

ALEXY, R. (2002) "Teoría de los derechos fundamentales". Madrid: Centro de Estudios Políticos y Constitucionales.

BERNAL, C. (2005) "El Derecho de los derechos". Bogotá: Universidad Externado de Colombia.

BERNAL, C. (2006) “El Neoconstitucionalismo a Debate”. Bogotá: Universidad Externado.

BERNAL, C. (2007) “El Neoconstitucionalismo y la normatividad en el derecho". Bogotá: Universidad Externado de Colombia.

CALDERÓN, J. (2011) “La constitucionalización del derecho privado. La verdadera historia del impacto constitucional en Colombia". Bogotá: Uniandes.

CAMACHO, A. (1978) "Recursos de casación y revisión en materia civil". Bogotá: Universidad Externado de Colombia. 
CARBONELL, M. (2007) "Teoría del Neoconstitucionalismo, Ensayos escogidos". Madrid: Trotta.

CAROFIGLIO, G. (2010) "El arte de la duda". Barcelona: Marcial Pons.

CARRIO, G. (1995) “Cómo estudiar y como argumentar un caso". Buenos Aires: ABELEDOPERROT.

COHEN, G. (2009) "Interpretation and Implied Terms in Contract Law". Virginia: University of Virginia.

COOTER, R. (2000) “Law \& economics”. New York: Addison Wesley Longman.

Corte Constitucional sentencia C 803 de 2000.

Corte Constitucional sentencia C 590 de 2005

Corte Constitucional sentencia C 590 de 2005.

Corte Constitucional Sentencia T 747 de 2009.

Corte Constitucional sentencia C 025 de 2010.

Corte Constitucional sentencia T 464 de 2012.

Corte Constitucional sentencia SU 198 de 2013.

Corte Constitucional sentencia C 279 de 2013.

Corte Constitucional sentencia C 367 de 2014.

Corte Constitucional sentencia T 750 de 2014.

Corte Constitucional sentencia T 103 de 2014.

Corte Constitucional sentencia T 098 de 2015.

CURZIO, L. (1998) “Toma de decisiones”. México: Instituto Federal Electoral.

DEVIS, H. (1985) "Teoría General del Proceso". Buenos Aires: Editorial Universidad.

ELSTER, J. (2007) "Explaining Social Behaviour. More Nuts and Bolts for the Social Sciences". Cambridge: University Press. 
HERBERT, S. (1985) "Human Nature and Politics. The Dialogue of Psychology with Political Science". American Political Science Review, vol. Ixxiv.

LÓPEZ, D. (2004) “Nuevas tendencias en la dirección judicial del proceso”. Bogotá: Consejo Superior de la Judicatura.

LÓPEZ, D. (2006) “Interpretación Constitucional". Bogotá: Universidad Nacional de Colombia.

LÓPEZ, H. (1983) “Instituciones de Derecho Procesal Civil”. Bogotá: Edit. ABC.

MORALES, H. (1983) “Técnica de casación civil”. Bogotá: Ediciones Rosaristas.

POSNER, R. (2011) “Cómo deciden los jueces”. Barcelona: Marcial Pons.

QUINCHE, M. (2015) “Derecho procesal constitucional colombiano. Acciones y procesos". Bogotá: Doctrina y Ley.

QUINCHE, M. (2015) “La acción de tutela”. Bogotá:Temis.

QUINCHE, M. (2013) "Vías de hecho. La acción de tutela contra providencias judiciales". Bogotá: Temis.

RIVERA, J. (2007) "La cuantificación del daño moral en los casos de lesión al honor, la identidad y la imagen". México: Revista Latinoamericana de derecho, Num. 7-8.

ROJAS, A. (2006) “Los principios en el derecho". En Revista Pensamiento Jurídico No. 16, Bogotá: Universidad Nacional de Colombia.

SÁCHICA, L. (2000) “Nuevo constitucionalismo Colombiano”. Bogotá: Temis.

SUAREZ, W. (2014) “El Rol del Juez en el estado Constitucional”, Revista lustitia, Colombia, vol. 12, p. 103-12. 